\title{
Critical Literature Review of the Homeopathic Compound Traumeel for Treatment of Inflammation
}

\author{
Dennis Grech'1, Jayant Velagala'1, Dennis J. Dembek ${ }^{1}$, Burton Tabaac ${ }^{2}$ \\ ${ }^{1}$ Department of Anesthesiology, New Jersey Medical School, Rutgers University, Newark, NJ, USA \\ ${ }^{2}$ Department of Neurology, Robert Wood Johnson School of Medicine, Rutgers University, New Brunswick, NJ, USA \\ Email: djd255@njms.rutgers.edu
}

How to cite this paper: Grech, D., Velagala, J., Dembek, D.J. and Tabaac, B. (2018) Critical Literature Review of the Homeopathic Compound Traumeel for Treatment of Inflammation. Pharmacology \& Pharmacy, 9, 67-83.

https://doi.org/10.4236/pp.2018.93006

Received: December 1, 2017

Accepted: March 28, 2018

Published: March 31, 2018

Copyright $\odot 2018$ by authors and Scientific Research Publishing Inc. This work is licensed under the Creative Commons Attribution-NonCommercial International License (CC BY-NC 4.0). http://creativecommons.org/licenses/by-nc/4.0/

\section{Open Access}

\begin{abstract}
Traumeel is a compound that is utilized by a wide variety of healthcare practitioners to treat inflammatory states. It is utilized extensively in Germany for multiple inflammatory conditions. The purpose of this document is to review and critique publications written about Traumeel and Traumeel S, a proprietary formulation. Furthermore, this review will determine if the literature supports substituting Traumeel for Non-Steroidal Anti-Inflammatory Drugs (NSAIDs) and corticosteroids or if adding Traumeel to NSAID and corticosteroid treatment protocols benefits patients with inflammation. Long-term use of NSAIDs and corticosteroids causes significant pathology leaving many patients without an effective treatment to manage their inflammatory condition. Traumeel does not have the severe side effect profile of NSAIDs and corticosteroids. There are important implications of the studies included in this review. The literature supports Traumeel as an effective alternative to NSAIDS and corticosteroids in preventing stomatitis for patients undergoing chemotherapy. Traumeel also provides pain-free outcomes following musculoskeletal and tissue injuries.
\end{abstract}

\section{Keywords}

Traumeel, Inflammation, Surgical Inflammation, Corticosteroid, Complementary Medicine, Homeopathy

\section{Introduction}

Traumeel is a compound that is utilized by a wide variety of healthcare practitioners to treat inflammatory states within the body. It is composed of various natural plant and mineral extracts, which target the inflammatory pathways fol- 
lowing soft-tissue injury. In the United States, the current mainstay of treatment for inflammatory states due to various conditions consists of corticosteroids and non-steroidal anti-inflammatory drugs (NSAIDs) [1]. Although highly effective, these medications have side effects that limit both their short and long term use in many patients [2]. The purpose of this comprehensive literature review is to present and critique publications written about Traumeel's use for treating patients with a variety of inflammatory conditions. This review also attempts to determine if the literature supports the substitution of Traumeel for NSAIDs and corticosteroids or the use of Traumeel in conjunction with these medications for treatment of certain inflammation conditions.

\section{Background}

Inflammation is the physiological and pathological response to cell injury, which results in the recruitment of leukocytes and plasma proteins to affected tissue and activation of tissue-resident macrophages causing para-inflammation [3]. The inflammatory response is beneficial in many instances, such as bacterial infection and traumatic tissue injury. If the process becomes unregulated, however, the inflammatory response that normally destroys and eliminates pathogens is also capable of injuring normal tissues [4]. First line management of an unregulated inflammatory response is to limit excessive inflammation [5].

While there are many types of insults that lead to an inflammatory response (i.e. bacterial infections and allergic reactions), this review focuses on the treatment of inflammation caused by musculoskeletal injuries and damage to mucosal membranes. The literature search revealed a paucity of quality research, which limits the scope of this review.

Acute inflammation caused by musculoskeletal injuries often leads to pain, joint instability and loss of function [6]. Conventional management of musculoskeletal injuries involves limiting pain, minimizing further tissue injury, restoring range of motion and improving voluntary muscle control [7]. First-line management is achieved via the rest, ice, compression, and elevation (RICE) protocol, which aims to reduce injury-related bleeding into muscle tissue.

Another pathologic inflammatory condition, mucositis, is a breakdown of mucosal membranes at any location along the gastrointestinal tract. Mucositis is experienced by up to $40 \%$ of cancer patients who receive 5 -flurouracil for chemotherapy and radiation therapy [8]. Those patients receiving 5-flurouracil experience moderate to severe mucositis, while $10 \%-15 \%$ have severe mucositis which limits the patient's ability to tolerate solid food and liquids [9].

Currently, the most prescribed treatment for inflammation secondary to mucositis relies on the use of corticosteroids in the oral, injection and topical forms as well as orally administered NSAIDs.

Corticosteroids have been shown to cause hyperglycemia, electrolyte disturbances, hypertension and hematologic abnormalities [10]. Prolonged use of corticosteroids can lead to suppression of the hypothalamic-pituitary-adrenal axis, 
Cushing's syndrome, osteopenia, immunosuppression and gastrointestinal side effects [11] [12].

Low doses of NSAIDs provide therapeutic benefit with a high safety index when used in the acute setting. Deleterious side effects of NSAIDs include heart attack, stroke, peptic ulcers, gastrointestinal bleeding, and kidney disease. Current limitations of these medications and their side effect profiles warrant an effective, safer and better-tolerated medication [13].

When assessing and weighing the benefits of the myriad of treatment regimens, it is imperative to consider patient preferences. It has been shown that clinical outcomes and patient compliance are significantly impacted when patients have their preferences discussed and honored [14]. Elements which influence a patient's preference include time to onset of pain relief, symptom recurrence, route of administration, consistency, and side effects of the treatment [15]. As traditional treatment regimens may be ineffective or cause unwanted side effects, patients often prefer alternative regimens [16]. Current trends demonstrate that complementary and alternative medicine regimens are being used more frequently [17]. Many studies show that patients prefer a combination of both standard of care therapy and complementary medicine measures rather than a single regimen alone.

\section{Traumeel, Current Use}

Traumeel is currently used worldwide for the treatment of inflammatory pathologies and is available in oral, topical, and injection forms [18]. Traumeel S is a specific formulation that contains highly diluted extracts of plants and minerals including Arnica montana, Calendula officinalis, Achillea millefolium, Matricaria chamomilla, Symphytum officinale, Atropa belladonna, Aconitum napellus, Bellis perennis, Hypericum perforatum, Chinacea angustfolia, Echinacea purpurea, Hamamelis virginica, Mercurius solubilis and Hepar sulfuris (Table 1). Traumeel $S$ is manufactured by the HEEL Company in Baden-Baden, Germany and follows the European Union guidelines for manufacturing practice for medicinal products [19]. The product has been available as an over the counter therapy in Germany, Australia, and Switzerland for the past 50 years.

Traumeel $S$ is used across Western Europe to treat inflammation caused by joint sprains, epicondylitis, arthroses, contusions, bursitis, and hematomas. The literature search identified studies focusing on Traumeel in the treatment of musculoskeletal injuries compared to corticosteroid and NSAID treatments. Additional studies have been conducted in the setting of chemotherapy-induced mucositis as both a preventative option and a treatment option [20].

Traumeel consists of dilute fractions of multiple different compounds that are thought to exert specific effects on various phases of the inflammatory response. Prior publications have documented Aconitum napellus, Matricaria recutita, Hamamelis virginiana, and Hypericum as having pain-relieving effects. Arnica montana, Calendula officinalis, Echinacea, and Symphytum have been shown to 
Table 1. Components of traumeel with corresponding dosages [26].

\begin{tabular}{cccc}
\hline $\begin{array}{c}\text { Components of } \\
\text { Traumeel [27] [28] }\end{array}$ & $\begin{array}{c}\text { Ointment } \\
\text { (per 100 g) }\end{array}$ & $\begin{array}{c}\text { Tablets } \\
\text { (per 300 mg) }\end{array}$ & $\begin{array}{c}\text { Ampoules for Injection } \\
\text { (per } 2.2 \mathrm{~mL} \text { ) }\end{array}$ \\
\hline Achillea millefolium & $90 \mathrm{mg}$ & $0.015 \mathrm{mg}$ & $0.0022 \mu \mathrm{L}$ \\
Aconitum napellus & $5 \mathrm{mg}$ & $0.03 \mathrm{mg}$ & $0.0132 \mu \mathrm{L}$ \\
Arnica Montana & $1.5 \mathrm{mg}$ & $0.15 \mathrm{mg}$ & $0.022 \mu \mathrm{L}$ \\
Atropa belladonna & $5 \mathrm{mg}$ & $0.0075 \mathrm{mg}$ & $0.022 \mu \mathrm{L}$ \\
Bellis perennis & $100 \mathrm{mg}$ & $0.06 \mathrm{mg}$ & $0.011 \mu \mathrm{L}$ \\
Calendula officinalis & $450 \mathrm{mg}$ & $0.15 \mathrm{mg}$ & $0.022 \mu \mathrm{L}$ \\
Chamomilla recutita & $150 \mathrm{mg}$ & $0.024 \mathrm{mg}$ & $0.0022 \mu \mathrm{L}$ \\
Echinacea angustfolia & $150 \mathrm{mg}$ & $0.06 \mathrm{mg}$ & $0.0055 \mu \mathrm{L}$ \\
Echinacea purpurea & $150 \mathrm{mg}$ & $0.06 \mathrm{mg}$ & $0.0055 \mu \mathrm{L}$ \\
Hamamelis virginiana & $150 \mathrm{mg}$ & $0.15 \mathrm{mg}$ & $0.022 \mu \mathrm{L}$ \\
Hepar sulfuris & $0.000025 \mathrm{mg}$ & $0.0000003 \mathrm{mg}$ & $0.000001 \mu \mathrm{L}$ \\
Hypericum perforatum & 0.00009 & $0.03 \mathrm{mg}$ & $0.0066 \mu \mathrm{L}$ \\
Mercurius solubilis & $0.00004 \mathrm{mg}$ & $0.0000003 \mathrm{mg}$ & $0.0000011 \mu \mathrm{L}$ \\
Hahnemanni & & $0.00000024 \mathrm{mg}$ & $0.0000022 \mu \mathrm{L}$ \\
Symphytum officinale & $0.01 \mathrm{mg}$ & &
\end{tabular}

accelerate wound healing. Edema has been studied and shown to be inhibited by Arnica montana, Hamamelis virginiana, Achillea millefolium, Aconitum napellus, Atropa belladonna, and Mercurius solubilus. Additional research suggests that there is a synergistic effect among the components of Traumeel [21].

There is evidence that Traumeel is involved in the microbiologic biochemical pathways regarding inflammation. While reducing acute inflammation similar to NSAIDS, Traumeel does not affect granulocyte function or human platelet adhesion in vitro [22]. There is evidence to suggest that Traumeel accelerates the healing process rather than inhibiting edema development directly. Interestingly, Traumeel has been studied for its role in increasing the production of transforming growth factor beta (TGF- $\beta$ ), thus increasing the production of regulatory lymphocytes [23]. Through TGF- $\beta$ production, other inflammatory cytokines including IL- 1 and TNF- $\alpha$ are prevented from up-regulating the inflammatory process [24]. Traumeel has also been studied for its indirect role regarding its inhibition of NK-kB and the activation of inflammatory cytokines [25].

\section{Methods for Literature Search}

A comprehensive literature search of PubMed and the Cochrane Library has been conducted to identify all studies that have been performed with Traumeel S. The literature search criteria for inclusion are depicted in Figure 1. The keywords used to identify all prior studies on Traumeel were: "Traumeel", "inflammation", "surgical inflammation", "corticosteroid", "complementary medicine", 


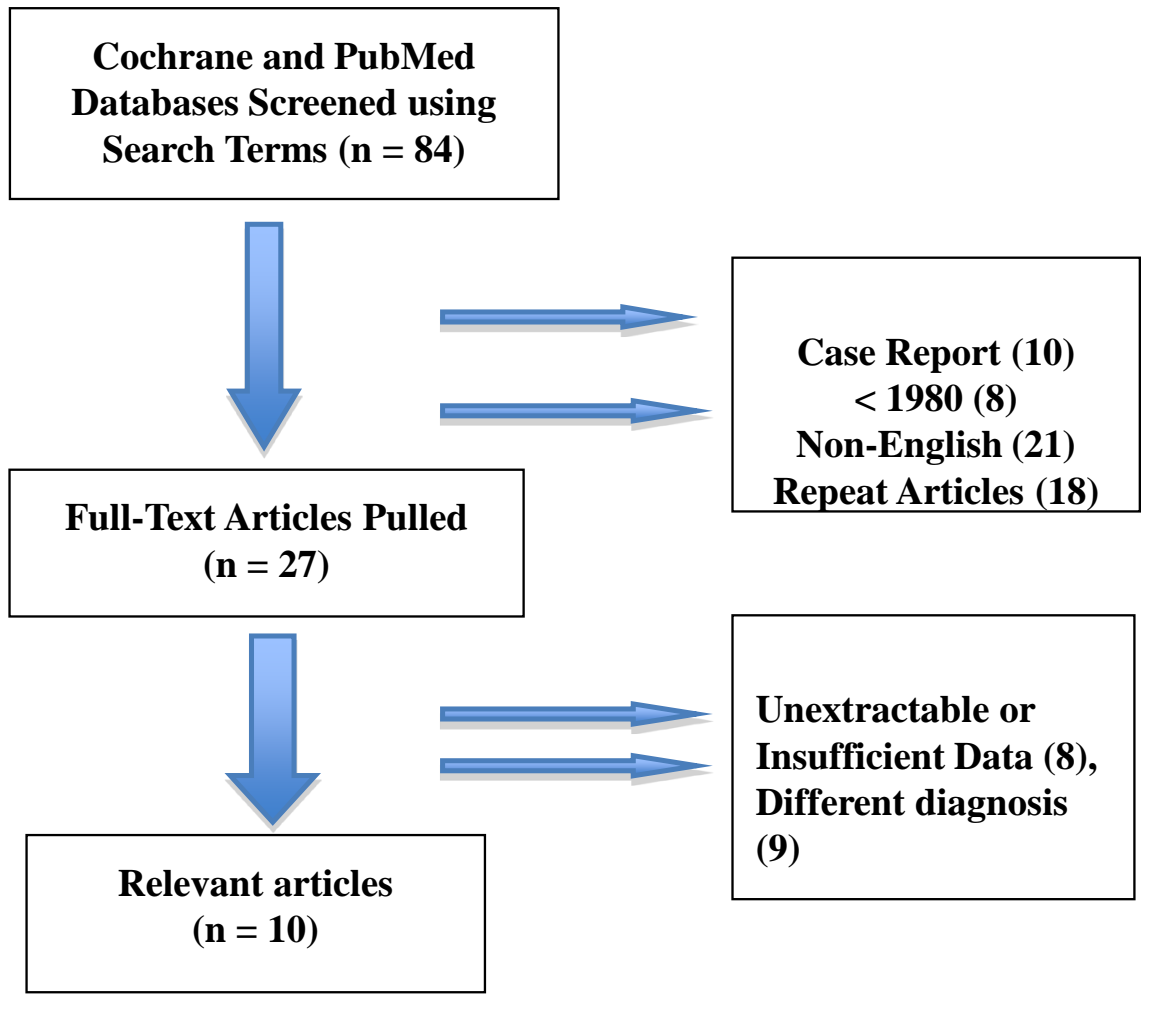

Figure 1. Diagram (or model) of inclusion criteria for selecting manuscript to include in comprehensive review.

and "homeopathy". These words were used in combination to search specific publications that most related to the topic in question. All literature published between 1980 and December 2015 reporting on efficacy, adverse events, and mode of action were included in this review. Inspection of the acquired full-text articles was performed to ensure that articles met all inclusion criteria. The publications were then dissected to extract the relatable studies, methods, and results that pertained to this particular literature review. Ample information was used from each publication such that the respective studies retained context as they relate to the overall results and clinical applications.

\section{Results}

Oberbaum et al. performed a randomized, placebo-controlled, double blind study on 32 patients between the ages of 3 - 25 who suffered from malignant disease and were undergoing stem cell therapy (SCT). The objective of this study was to compare the area under the curve (AUC) and the time to worsening of stomatitis using mouth-rinsing solutions of Traumeel $S$ or placebo in conjunction with standard oral care for mucositis. Treatment was started on day two following SCT. Stomatitis was evaluated in each patient using the World Health Organization (WHO) grading system for mucositis. The AUC was equivalent to the sum of the grade for each patient every day from the start of treatment. Five patients in the Traumeel S group did not develop stomatitis compared with one 
patient from the placebo group. The mean AUC for the Traumeel S curve was 10.4 and the mean AUC for the placebo group was 24.3 with a significance of $p<$ 0.01 , suggesting that Traumeel $S$ reduced the symptom severity and duration of stomatitis when compared with the placebo. Seven patients in the Traumeel $S$ group suffered worsening of stomatitis compared with 14 in the placebo group with a significance of $p<0.001$, suggesting symptoms were less likely to worsen in patients treated with Traumeel S. As a randomized and double blind study with clear methodology and comparative study groups, the results suggest that Traumeel S significantly reduces the severity and duration of chemotherapy-induced oral stomatitis following SCT. In order to increase the power of the study, a larger sample size is indicated. In addition, though the ages of the patients in the study ranged from $3-25$, the majority of participants were under the age of 15; therefore, generalization of the study results to all patients undergoing SCT must be used with caution. Furthermore, the subjective scoring system must be taken into consideration when interpreting the study results.

Sencer et al. sought to replicate the results of the Oberbaum et al. study on a larger scale with a multi-center, double blind, randomized placebo controlled trial. The study enrolled 195 patients at 28 different children's oncology centers and two Israeli institutions between the ages of 3 - 25 years old who were undergoing myeloablative hematopoietic stem cell transplant (HSCT). Participants started treatment one day before transplant by rinsing their mouth five times daily with the selected treatment and ended after 20 days of treatment or when the patient met the specified completion criteria. Efficacy was determined using the AUC of the three-grade modified Walsh scale for mucositis recorded daily and the five-grade WHO oral toxicity scale. Of the 190 patients enrolled in the study, full data was obtained from 106 patients. The AUC computed for the Walsh scale in patients treated with Traumeel S was 71.7 compared to 69.8 in the placebo group with a $43 \%$ probability that a patient treated with Traumeel $S$ would have a lower AUC than a patient treated with placebo on a $95 \%$ confident interval. Overall, no significant differences were found on monitoring the effects of Traumeel S solution versus placebo in the treatment of HSCT-induced oral mucositis. The trial conducted by Sencer et al. had a greater power than the previous study performed by Oberbaum et al. as well as equally comparable study groups and clearly defined methodology. Unfortunately, the data collection and administration between the many centers included in the study question the reliability and accuracy of the study results. In several of the centers included, data was collected on only five patients and was performed by a different person at each collection. In addition to a subjective scoring system and lack of compliance, an additional study to observe how administration of Traumeel S effects the severity and duration of HSCT-induced oral mucositis is needed.

Porozov et al. studied the mode of action of Traumeel and its effects on human leukocyte function in vitro, specifically $\mathrm{T}$-cell activation and the secretion of inflammatory cytokines IL- $1 \beta$, TNF- $\alpha$ and IL- 8 by T-cells, monocytes, endo- 
thelial cells and gut epithelial cells. Secretion of IL-1 $\beta$ and IL- 8 was measured by seeding HT-29 and HUVEC cell lines and then incubating well plates with increasing dilutions of Traumeel for 24,48 , or 72 hours. The results were then compared to cells untreated with Traumeel. TNF- $\alpha$ secretion was measured 24 hours before and after exposure to Traumeel. All cytokine measurements were performed using ELISA. Jurkat and THP-1 cell lines were also exposed to Traumeel, treated with activators, and cytokine secretion was measured. In the Jurkat and THP-1 cell lines, Traumeel was observed to cause a dose-dependent inhibition of IL-1 $\beta$ secretion with the highest inhibition at the lowest concentrations $\left(18 \mathrm{pg} / \mathrm{ml}\right.$ at $10^{-7}, 60 \mathrm{pg} / \mathrm{ml}$ at $\left.10^{-1} ; p<0.05\right)$. At dilutions of $10^{-3}-10^{-7}$, Traumeel was found to significantly inhibit TNF- $\alpha$ secretion for Jurkat and THP-1 cells, which was also more effective after longer incubation. This occurred irrespective of pretreatment with activators. The study also examined whether Traumeel could modulate TNF- $\alpha$ secretion from human T-cells. Results showed inhibition of TNF- $\alpha$ secretion at dilutions of $10^{-1}-10^{-4}(p<0.05)$. This study concluded that a possible mechanism of action for Traumeel is to inhibit the secretion of pro-inflammatory cytokines IL- $1 \beta$, TNF- $\alpha$, and IL- 8 due to their results in an in vitro setting. Due to the dose-dependence observed, the study also concluded that these actions are not due to a toxic effect on cells. The results suggest that further investigation into the mechanism of action of Traumeel is needed to demonstrate causative relationship between the inhibition of cytokines in vitro and the reported clinical effects. It is also suggested that because Traumeel is a multi-component preparation and the results observed in this study were dose dependent, investigation into effects of the individual components of Traumeel is required to identify whether the observed effects are a result of synergistic effects of multiple components or the individual components themselves [29].

Pilat et al. put forth a study to investigate the potential effects of Traumeel (Trl4) on the exercise-induced immune response. This was assessed via a randomized, double blind controlled trial in which 40 healthy males were given tablets of Trl4 or placebo for 24 hours following a standardized strenuous exercise protocol. The study measured the area under the curve (AUC) of pro- and anti-inflammatory immune regulators with the primary endpoints of measuring changes in IL- 6 and hsCRP. There was no significant difference observed between the Trl 4 and placebo groups for IL- 6 and hsCRP, but there were several other differences identified among immune response modifiers. In the Trl4 group, there was a lower level of exercise-induced leukocytosis and neutrocytosis compared to the placebo group $(p<0.01)$. Among the soluble inflammatory mediators, IL-1 $\beta$ and IL-1 $\alpha$ were seen to increase more in the Trl4 group as compared to the placebo and granulocyte-monocyte colony stimulating factors (GM-CSF) was observed to be lower in the Trl4 group. Colony stimulating factors have been found to play a role in the exercise-induced response of peripheral neutrophils. Because Trl4 was noted to decrease GM-CSF, this study suggested a weakened GM-CSF response was responsible for the decrease in peripheral 
neutrophils. There was no significant difference observed between the groups for other functionally related cytokines, including IFN- $\Upsilon$, IL-3, IL-5, IL-10, IL12p40, IL12p70, TNF- $\alpha$ and TNF- $\beta$.

Exhaustive exercise has been shown to cause considerable changes to the immune response. This study set forth to determine the physiologic effects at the cellular level of Trl4 on the immune response following exercise. The data collected suggests that treatment with $\operatorname{Tr} 14$ following strenuous exercise attenuates the innate immune response and strengthens the pro-inflammatory cytokine response when compared to a placebo. While the study inclusion criteria were well specified and the two study groups were equally comparable, the discussion of all components involved in the immune response rather than a focus on a specific subset or variable raises question as to the significance of the study results. Additionally, the findings of an enhanced pro-inflammatory cytokine response are contradictory to prior in vitro studies performed by Porozov et al. in which they found significant inhibition of IL- $1 \beta$ production by Trl4.

A study conducted by Gonzalez de Vega et al. aimed to compare the effectiveness and tolerability of topically applied Traumeel versus Diclofenac in the setting of mild to moderate acute ankle sprains. The study was a multicenter, randomized and controlled study with 449 physically active adults who had sustained grade one or grade two ankle sprains in the last 24 hours. Patients received either two grams of Traumeel gel (T-G), Traumeel ointment (T-O), or Diclofenac gel (D-G) applied to the injured area three times a day. Primary endpoints were reported on day seven as percentage of change in the visual analogue scale (VAS) score from their initial assessment, with a score of zero being no pain and 100 being worst imaginable pain, and the foot and ankle mobility measure (FAAM), a self-reported questionnaire to assess the physical function of individuals with disorders of the leg, foot and ankle. Secondary endpoints used the same scales but were measured on days four, seven, 14, and 42. There were no statistically significant changes found between groups. Median VAS score reductions on day seven were reported as $60.6 \%$ for the T-O group, $71.1 \%$ for the T-G group and $68.9 \%$ for the D-G group, with approximately $90 \%$ of patients returning to normal activities by day $14-19$. This study with a large sample size and well described method suggest that both T-G and T-O are not inferior to traditional NSAID use in the treatment of mild to moderate ankle sprains and may increase the treatment options for patients wanting to avoid the use of topical NSAIDs. On the other hand, interpretation of the study must be done with caution when considering visual differences in the T-O preparation compared to the T-G and D-G as well as the subjective nature of the VAS and FAAM scoring systems. Additionally, funding for this study was provided by Biologische Heilmittel Heel GmbH, the company that manufactures Traumeel. This may introduce slight bias in the interpretation of study results.

Birnesser et al. performed an observational, non-randomized study to compare Traumeel S with standard NSAID therapy for the symptomatic treatment of 
epicondylitis. The study was composed of 184 patients ages 14 - 88 across primary care centers in Germany in which the treatment option was chosen by the patient. Patients in the Traumeel $S$ group were allowed further injections of Traumeel S but not oral NSAIDs. The primary endpoints evaluated were pain with local pressure, pain on movement, pain at rest, and changes in extensional and torsional joint mobility. Each was assessed on a five-point scale at the beginning of treatment and two weeks following treatment. Because there may be differences in the types of patients who choose a homeopathic remedy compared to traditional treatment, a propensity score analysis was constructed to balance the observed variances between groups. Similar levels of improvement were seen for all five evaluated variables in both treatment groups. Patients in the Traumeel $S$ group showed greater improvements in pain at rest and changes in extensional and torsional joint mobility when compared to the NSAID group. Both patient groups rated the treatment as "very good" and "good" and $87.7 \%$ of patients in the Traumeel S group rated the tolerability as "very good" compared to $44.9 \%$ in the NSAID group. In terms of differences among treatment groups, because the groups were highly similar, the adjustment using the propensity score had no influence on the evaluation of respective treatments. As a non-inferiority study to compare the efficacy of Traumeel $S$ with standard NSAID therapy in the treatment of epicondylitis, the results concluded that Traumeel $S$ is equivalent to NSAIDs in all variables for the short-term, localized treatment of epicondylitis and may be a suitable alternative to NSAIDs due to its high tolerability profile. As an observational cohort study, there was possibility for large differences between treatment groups. This was accounted for via propensity score analysis to balance observed co-variates. Additionally, the subjective nature regarding the terminology of describing treatment as "satisfactory," "good," and "very good," must be considered when interpreting the study results. A conflict of interest may also be represented in this study due to its funding by Biologische Heilmittel Heel, GmbH, the manufacturer of Traumeel.

A controlled, double blind study performed by Bohmer et al. aimed to compare and assess the effectiveness of commercially available Traumeel S ointment and Traumeel ointment which containing only six constituents versus a placebo. The study contained 102 healthy patients between the ages of 18 - 50 with visible or palpable tissue alterations only requiring outpatient treatment. Participants were divided into three comparable groups. The primary endpoints were regression of swelling measured on day one, five, and 15 and reduction of skin temperature, both measured and compared with the uninjured contralateral side. Secondary effectiveness criteria were indicated as increased maximum muscle force, reduction of pain intensity, and time required to return to physical training. Patients received the first treatment no more than four days following the initial injury and applied the medication twice daily for the following 15 days. Both Traumeel groups were found to be superior to placebo in reduction of swelling after 15 days with a significance of $p<0.0067$; however, no significant 
difference was found among the three treatment groups for reduction in skin temperature. In comparison of secondary endpoints, the two Traumeel groups were superior to the placebo. By the $15^{\text {th }}$ day the maximum muscle force had approached the muscle force of the uninjured side and both Traumeel groups demonstrated greater reduction in the cumulative pain index $(p<0.0016)$ as well as resumption of physical training sooner than those treated with placebo. In this study, Traumeel $\mathrm{S}$ was found to be superior to placebo in the treatment of sports injures with regards to reduction of swelling, maximum muscle force, pain index and return to physical activity. The power of this study would be increased by a larger sample size. The inclusion criteria and methodology for treatment application was well specified and there were no significant differences among treatment groups. Interpretation of the data must be performed with caution due to the subjective nature of variation in physician and patient assessment of pain parameters, but the results of the study are comparable to several earlier studies on the effectiveness of Traumeel $\mathrm{S}$ in the treatment of sports injuries when compared to placebo.

Schneider et al. conducted a study to assess the daily use, effectiveness, and safety of Traumeel compared with conventional treatments in patients with trauma and injury. An observational cohort study containing 133 patients was conducted for the treatment of acute ankle sprains, sports injuries and traumatic hemarthroses. Patients in the Traumeel group used Traumeel as a monotherapy or in conjunction with other homeopathic products and patients in the control group were treated only with conventional medications. There was no significant difference between the two groups. The primary outcome was measured as the rate of resolution of the main symptoms at the end of therapy recorded on a three-point scale for severity after a maximum of three months. Secondary endpoints were measured as the time to symptomatic improvement and treatment outcome assessed by the physician. The most common symptoms reported were pain and inflammation. Complete resolution of symptoms was reported by $59.4 \%$ of patients treated in the homeopathic group compared with $57.8 \%$ of patients in the conventional treatment group. This study concluded that Traumeel is as effective as conventional therapy in the treatment of mild-moderate injuries and trauma as well as safer and better tolerated. The study encompassed 81 different physicians with varying backgrounds in conventional therapies and a diversity of injuries among the treatment groups. While a selection bias may have been present, there were no significant differences among study groups. Interpretation of the results must take into account the wide variety of conventional treatments used in the control groups as well as the absence of a specified methodology for treatment between both groups. A conflict of interest may exist due to funding by the manufacturer of Traumeel, Biologische Heilmittel Heel, $\mathrm{GmbH}[30]$.

Singer et al. conducted a randomized, double blind, placebo controlled trial to evaluate the efficacy of oral administration of Traumeel $\mathrm{S}$ tablets compared to 
placebo following surgery for hallux valgus correction. The primary endpoints of this study were to measure pain and the need for primary analgesics over a two week period following surgery. Eighty patients were enrolled and instructed to take two tablets of medication five times a day for the first three days and then three times daily up to a total of 14 days following surgery. They also were asked to complete a pain diary to record maximum daily pain scores at rest using a self-administered, horizontal 11-point numerical rating score. Statistical analysis was performed using the AUC of pain scores recorded over the study period and the means were compared between groups. The mean AUC for pain scoring with Traumeel S was $55.4 \pm 25.5$ compared to $57.4 \pm 25.7$ in the placebo group with a $p$-value of 0.89 , indicating no significant difference between groups. In terms of primary analgesics consumed, the AUC for the Traumeel group was $15.6 \pm 12.2$ compared to $16.0 \pm 11.9$ in the placebo group, with a p-value of 0.74 again indicating no significant difference between groups. The one significant difference that was established was found on post-operative day one with a pain score of 4.0 in the Traumeel group and 5.6 in the placebo group with a p-value of 0.04 , suggesting further testing of Traumeel in the immediate post-operative period may be indicated. The results of this study do not support a previously performed study by the same group in 2007 in which findings suggested a 30\% improvement in post-operative pain and a decreased trend for the use of primary analgesics with the use of Traumeel. Unfortunately, these results are not published, thus they cannot be analyzed for the purpose of this paper. Although the study groups were similar in this study and the method clearly stated, the use of a subjective scoring system for pain severity indicates the results should be interpreted with caution. Additionally, when compared to the prior study, an oral formulation of Traumeel was used instead of an injection solution, which suggests the need for further evaluation of which specific Traumeel formulation has greater efficacy. A second possible limitation when compared to other studies of Traumeel is the administration of oral medication being compared against topically applied or injected solutions [31].

Zilinskas et al. performed an in vitro study to investigate the effect of Traumeel $\mathrm{S}$ on the antioxidant capacity of venous blood, plasma, and serum in patients with periodontitis compared to healthy patients. The study consisted of 21 patients evaluated for periodontal status using Russell's periodontal index and a control group of 22 patients with healthy periodontal tissues. Blood was collected from both sets of patients and analyzed for nitro blue tetrazolium (NBT) reduction in blood, plasma and serum using spectrophotometry. There was a statistically significant elevation in leukocyte count in the periodontitis group when compared to the control group with a p-value $<0.05$. The antioxidant capacity of blood plasma was significantly higher in the periodontitis group when compared to the control group, but the antioxidant capacity of serum was lower with a statistical significance of $p<0.05$. Traumeel $\mathrm{S}$ was not found to have any effect on the antioxidant capacity within either group. This study had a 
well-established methodology for the measurement of antioxidant capacity of all blood products. The results of increased leukocyte count and antioxidant capacity in blood plasma could be further enhanced by a study including multiple types of chronic inflammation. Additionally, because Traumeel S is a combination of multiple plant extracts and minerals and has frequently been used in the treatment of chronic inflammation, further study is warranted to determine if possible antioxidant capacity is a result of a metabolite from one of its individual components [32].

The results of each individual study are summarized below (Table 2).

Table 2. Summary of the literature Review.

\begin{tabular}{|c|c|c|c|c|c|}
\hline Authors & Study Design & $\begin{array}{l}\text { Sample Size } \\
(\mathrm{N})\end{array}$ & Instrument & Main Finding & $\begin{array}{c}\text { Potential Clinical } \\
\text { Application }\end{array}$ \\
\hline $\begin{array}{l}\text { Oberbaum } \\
\text { et al. }[8]\end{array}$ & $\begin{array}{l}\text { Randomized, } \\
\text { placebo-controlled, } \\
\text { double blind }\end{array}$ & $\mathrm{N}=32$ & $\begin{array}{l}\text { WHO grading for } \\
\text { mucositis }\end{array}$ & $\begin{array}{l}\text { Traumeel S reduces } \\
\text { duration and severity } \\
\text { of stomatitis }\end{array}$ & $\begin{array}{l}\text { Efficacy in treating } \\
\text { stomatitis in patients } \\
\text { with } \\
\text { chemotherapy }\end{array}$ \\
\hline Sencer et al. [20] & $\begin{array}{l}\text { Randomized, } \\
\text { placebo-controlled, } \\
\text { double blind }\end{array}$ & $\mathrm{N}=195$ & $\begin{array}{l}\text { Three-grade modified } \\
\text { Walsh scale for } \\
\text { mucositis; } \\
\text { WHO Oral toxicity Scale }\end{array}$ & $\begin{array}{l}\text { No difference in } \\
\text { treatment of stomatitis }\end{array}$ & Unknown \\
\hline Porozov et al. [29] & In vitro & $\mathrm{N}=24$ & IL-1B, TNFa and IL-8 & $\begin{array}{l}\text { Traumeel lowers levels of IL-1B, } \\
\text { TNF-a and IL-8 }\end{array}$ & $\begin{array}{l}\text { Inhibit chronic } \\
\text { inflammation }\end{array}$ \\
\hline Pilat et al. [7] & $\begin{array}{l}\text { Randomized, } \\
\text { placebo-controlled, } \\
\text { double blind }\end{array}$ & $\mathrm{N}=40$ & IL-6 and hsCRP & $\begin{array}{l}\text { Trammel lowered } \\
\text { leukocytosis and } \\
\text { neutrocytosis, but not } \\
\text { IL- } 6 \text { and hsCRP }\end{array}$ & Unknown \\
\hline $\begin{array}{l}\text { Gonzalez de Vega } \\
\text { et al. [6] }\end{array}$ & $\begin{array}{l}\text { Randomized, controlled } \\
\text { study }\end{array}$ & $\mathrm{N}=449$ & VAS and FAAM scores & $\begin{array}{l}\text { No difference in pain } \\
\text { improvement in epicondylitis }\end{array}$ & $\begin{array}{l}\text { Alternative therapy } \\
\text { for orthopedic injury }\end{array}$ \\
\hline Birnesser et al. [19] & $\begin{array}{l}\text { Observational, } \\
\text { non-randomized study }\end{array}$ & $\mathrm{N}=184$ & $\begin{array}{l}\text { Questionnaire with } \\
\text { "good" or "very good" } \\
\text { response }\end{array}$ & $\begin{array}{l}\text { Trameel S reduces pain and } \\
\text { increases mobility in } \\
\text { epicondylitis }\end{array}$ & $\begin{array}{l}\text { Alternative therapy } \\
\text { for orthopedic } \\
\text { injury }\end{array}$ \\
\hline Bohmer et al. [26] & $\begin{array}{l}\text { Controlled, double-blind } \\
\text { study }\end{array}$ & $\mathrm{N}=102$ & $\begin{array}{l}\text { Swelling and skin } \\
\text { temperature }\end{array}$ & $\begin{array}{l}\text { Trameel S reduces } \\
\text { swelling and skin } \\
\text { temperature following injury }\end{array}$ & $\begin{array}{l}\text { Efficacy in treating } \\
\text { soft tissue injury }\end{array}$ \\
\hline Schneider et al. [5] & Observational cohort study & $\mathrm{N}=133$ & $\begin{array}{l}3 \text { point scale of pain } \\
\text { reporting }\end{array}$ & $\begin{array}{l}\text { No difference in pain } \\
\text { improvement following trauma } \\
\text { and injuries }\end{array}$ & Unknown \\
\hline Singer et al. [31] & $\begin{array}{l}\text { Randomized double blind } \\
\text { placebo study }\end{array}$ & $\mathrm{N}=80$ & $\begin{array}{l}\text { 11-point numerical } \\
\text { rating pain score }\end{array}$ & $\begin{array}{l}\text { No difference in pain } \\
\text { improvement following } \\
\text { orthopedic surgery } \\
\text { following Traumeel S } \\
\text { administration }\end{array}$ & Unknown \\
\hline Zilinskas et al. [30] & In vitro & $\mathrm{N}=43$ & $\begin{array}{l}\text { Leukocyte count and the } \\
\text { Antioxidant capacity of } \\
\text { the blood and serum }\end{array}$ & $\begin{array}{l}\text { Increase in antioxidant } \\
\text { activity in blood, but increase in } \\
\text { leukocyte count in patients with } \\
\text { periodontitis following } \\
\text { Traumeel S administration }\end{array}$ & Unknown \\
\hline
\end{tabular}




\section{Discussion}

Many of the articles reviewed demonstrate that Traumeel can decrease the incidence or severity of certain disease states that are associated with inflammation.

Oberbaum et al. and Sencer et al. looked at stomatitis in patients undergoing chemotherapy. These studies differ as opposite conclusions were derived regarding the statistical significance between the Traumeel and placebo groups. Although both studies were double blind and randomized placebo-controlled trials, there were several key differences. Oberbaum et al. was a single-center study that included 32 patients with various malignancies. Sencer et al. was a multi-center study with 195 patients who were specifically undergoing hematopoietic stem cell transplant (HSCT). Although both studies examined data via analysis of AUC data, Sencer et al. also used the WHO oral toxicity scale for analysis. Each study reached different conclusions. Sencer et al. stated there was no statistically significant difference between Traumeel and placebo groups in preventing HSCT-induced oral mucositis. Although Sencer et al. had a greater power than Oberbaum et al. (195 patients compared to 32 patients), variation of data collection and administration between the many centers included in Sencer's study question the reliability and accuracy of the results.

Porozov et al. stated that Traumeel significantly decreased the concentration of inflammatory mediators TNF- $\alpha$ and IL- $1 \beta\left[10^{-1}-10^{-4}, p<0.05 ; 18 \mathrm{pg} / \mathrm{ml}\right.$ at $10^{-7}, 60 \mathrm{pg} / \mathrm{ml}$ at $10^{-1}, p<0.05$ ]. It was also shown to preserve the populations of cell lines needed to combat infection.

Traumeel has been shown to be of benefit in the treatment of certain musculoskeletal injuries when compared to glucocorticoids and NSAIDs. The studies looked at a variety of injuries including trauma and postoperative pain following orthopedic surgery.

Gonzalez de Vega et al. examined pain relief following ankle sprains and the authors demonstrated that there was no significant difference between the Diclofenac and Traumeel treatment groups [Median VAS score reductions are $60.6 \%$ in T-O group, $71.1 \% \mathrm{~T}-\mathrm{G}$ group and $68.9 \%$ for the D-G group]. This study was conducted as a multi-center, randomized and controlled trial with 449 physically active adults. The research quantified pain improvement precisely using a Visual Analogue Score. Birnesser et al., another musculoskeletal injury study, described improvement in pain relief as either "very good" or "good".

Birnesser et al. was a multi-center, observational, non-randomized study with 184 patients. The results suggest that Traumeel can replace NSAIDs as the standard of care in the short-term treatment of epicondylitis. The authors subjectively described improvement in pain relief as "very good" or "good".

There were two studies that analyzed the effectiveness of Traumeel for sports injuries. Bohmer et al. conducted a controlled, double blind study with $102 \mathrm{pa}-$ tients. The authors demonstrate that Traumeel $S$ is superior to placebo in terms of reduction of swelling, maximum muscle force, pain index, and return to physical activity [After the $15^{\text {th }}$ day, $-4.38(1.810)$ in Traumeel $S$ group versus 
$-3.46(1.540)$ in placebo, $p<0.0067 ;-2.32(4.374)$ in Traumeel S group versus -2.94 (8.866) in placebo, $p<0.0016 ; 1.0(0.67)$ in Traumeel $S$ group versus 1.8 (0.96) in placebo, $p<0.0007 ; 12.1$ (2.56) in Traumeel $S$ group versus 13.5 (2.25) in placebo, $p<0.002$ ]. This study was unique in that it divided its cohorts into Traumeel, Traumeel S, and placebo. The primary endpoints to measure effectiveness were reduction in swelling and skin temperature rather than reduction of pain.

Schneider et al. is an observational cohort study consisting of 133 patients. The study divided its cohorts into exclusively Traumeel and Traumeel as an adjunct to conventional therapy. Primary outcomes were reported as resolution of pain symptoms.

In a study on postoperative pain following orthopedic surgeries by Singer et al., there was no statistically significant improvement in pain-free outcomes [The mean AUC with Traumeel S was $55.4 \pm 25.5$ versus $57.4 \pm 25.7$ in the placebo group with $p<0.89$ ].

The periodontitis study by Zilinskas et al. found that Traumeel did not increase the antioxidant capacity of blood in either the control or periodontitis group $[p>0.05]$.

The majority of studies separated patient groups in two ways. The cohorts were divided into either placebo versus Traumeel $S$ or conventional treatment versus Traumeel S. Only one study, Schneider et al., compared Traumeel with other homeopathic treatments versus conventional treatment.

Traumeel offers several advantages over traditional NSAIDs. For one, it is a natural compound. NSAIDs are synthetic compounds and are associated with more severe side effects. Traumeel has a low side effect profile with less incidence of side effects such as Cushing's syndrome, myocardial infarction, hypertension, heart failure, blood dyscrasias, rashes, gastrointestinal bleeding and liver damage (all of which are traditionally associated with NSAIDs). Traumeel is a more cost effective formulation than the most widely used forms of NSAIDs. It has been demonstrated to be a tolerable medication both in oral and topical forms [31] [32]. The reactions to the topical form of Traumeel were mild and transient and included redness, pruritus, and the sensation of heat [33]. One study examined the clinical safety of the oral version of Traumeel. The authors demonstrated that there were no differences in vitals or laboratory data at baseline or at the end of the study with the use of Traumeel. The most common side effects were headache, diarrhea, and nausea, which resolved with continued use of Traumeel.

\section{Conclusions}

There are many important implications of the studies included in this review.

Traumeel $S$ is an effective alternative to NSAIDs and corticosteroids in preventing stomatitis for patients undergoing chemotherapy. Of the two studies that examined this, Oberbaum et al. determined that Traumeel S significantly 
reduced the severity and duration of chemotherapy-induced oral stomatitis following stem cell therapy [Mean AUC for Traumeel S was 10.4 versus mean AUC for placebo group was 24.3, $p<0.01]$.

Traumeel S provides better pain-free outcomes following musculoskeletal and tissue injuries. Of the studies that analyzed the impact of Traumeel on tissue injuries, two reports demonstrated a significant impact. Birnesser et al. stated that Traumeel S could replace NSAIDs as conventional therapy [71\% in Traumeel S group versus $44.2 \%$ in control group, $p<0.013$. Bohmer et al. stated that Traumeel $S$ reduces swelling, maximum muscle force, pain index, and return to physical activity. [After $15^{\text {th }}$ day, -4.38 (1.810) in Traumeel S group versus -3.46 (1.540) in placebo, $p<0.0067 ;-2.32(4.374)$ in Traumeel $\mathrm{S}$ group versus -2.94 (8.866) in placebo, $p<0.0016 ; 1.0(0.67)$ in Traumeel $\mathrm{S}$ group versus $1.8(0.96)$ in placebo, $p<0.0007 ; 12.1$ (2.56) in Traumeel $S$ group versus 13.5 (2.25) in placebo, $p<0.002]$.

Porozov et al. looked at the secretion of inflammatory mediators such as IL-1 $\beta$, TNF- $\alpha$ and IL-8 by T-cells, monocytes, endothelial cells and guts epithelial cells. The study detailed that patients who received Traumeel had decreased levels of all three mediators. Traumeel was shown to decrease the potentially damaging effects of an inflammatory response while preserving the populations of cell lines needed to combat infection.

Despite the aforementioned studies on Traumeel, several unanswered questions remain. Multiple investigators state in their manuscripts that no single compound in Traumeel has been identified as the anti-inflammatory component. A systematic approach toward isolating a single chemical compound with potent anti-inflammatory activity is essential to promoting the use of Traumeel in Western medicine. Subsequent investigations would absolutely be warranted to address this uncertainty.

An alternate theory of the efficacy of Traumeel attributes it to the combined effects of multiple compounds. Currently, there is no consensus among investigators as to what combination of components is integral to the anti-inflammatory activity of Traumeel.

It is difficult to quantify the variability of pain scores and outcomes among patients and among the unique studies. Employing a standardized pain scale, such as the one used by Gonzalez de Vega et al., would make it easier to compare outcomes of pain relief among different studies in the future.

There is a poverty of sources that have examined clinical outcomes comparing Traumeel and NSAIDs. Further studies would be helpful in order for stronger conclusions about Traumeel's potential for inflammation to be discovered.

In conclusion, the literature reviewed in this manuscript identifies Traumeel as a potential mainstay of treatment for inflammation with minimal side effects as compared to current medical regimens. However, further investigations of Traumeel are warranted to identify mechanism of action, best route of administration, and most effective treatment regimen. 


\section{References}

[1] Nordqvist, C. (2015) Inflammation: Treatments.

[2] Jin, J. (2015) Nonsteroidal Anti-Inflammatory Drugs. JAMA, 314, 1084. https://doi.org/10.1001/jama.2015.9936

[3] Medzhitov, R. (2008) Origin and Physiological Roles of Inflammation. Nature, 454, 428-435. https://doi.org/10.1038/nature07201

[4] Kumar, V. and Abbas K, F.N. (2005) Robbins and Cotran Pathologic Basis of Disease. Elsevier Saunders, Amsterdam.

[5] Schneider, C. (2011) Traumeel-An Emerging Option to Nonsteroidal Anti-Inflammatory Drugs in the Management of Acute Musculoskeletal Injuries. International Journal of General Medicine, 4, 225-234. https://doi.org/10.2147/IJGM.S16709

[6] Gonzalez de Vega, C., et al. (2013) Traumeel vs. Diclofenac for Reducing Pain and Improving Ankle Mobility after Acute Ankle Sprain: A Multicentre, Randomised, Blinded, Controlled and Non-Inferiority Trial. International Journal of Clinical Practice, 67, 979-989. https://doi.org/10.1111/ijcp.12219

[7] Pilat, C., et al. (2015) Exploring Effects of a Natural Combination Medicine on Exercise-Induced Inflammatory Immune Response: A Double-Blind RCT. Scandinavian Journal of Medicine \& Science in Sports, 25, 534-542. https://doi.org/10.1111/sms.12265

[8] Oberbaum, M., et al. (2001) A Randomized, Controlled Clinical Trial of the Homeopathic Medication TRAUMEEL S in the Treatment of Chemotherapy-Induced Stomatitis in Children Undergoing Stem Cell Transplantation. Cancer, 92, 684-690. https://doi.org/10.1002/1097-0142(20010801)92:3<684::AID-CNCR1371>3.0.CO;2\#

[9] Rubenstein, E.B., et al. (2004) Clinical Practice Guidelines for the Prevention and Treatment of Cancer Therapy-Induced Oral and Gastrointestinal Mucositis. Cancer, 100, 2026-2046. https://doi.org/10.1002/cncr.20163

[10] Buchman, A.L. (2001) Side Effects of Corticosteroid Therapy. Journal of Clinical Gastroenterology, 33, 289-294. https://doi.org/10.1097/00004836-200110000-00006

[11] Fisher, D.A. (1995) Adverse Effects of Topical Corticosteroid Use. Western Journal of Medicine, 162, 123-126.

[12] Laine, L. (2003) Gastrointestinal Effects of NSAIDs and Coxibs. Journal of Pain and Symptom Management, 25, 32-40. https://doi.org/10.1016/S0885-3924(02)00629-2

[13] Vanden Bossche, L. and Vanderstraeten, G. (2015) A Multi-Center, Double-Blind, Randomized, Placebo-Controlled Trial Protocol to Assess Traumeel Injection vs Dexamethasone Injection in Rotator Cuff Syndrome: The TRAumeel in ROtator Cuff Syndrome (TRARO) Study Protocol. BMC Musculoskeletal Disorders, 16, 8. https://doi.org/10.1186/s12891-015-0471-z

[14] Brazier, J.E., Dixon, S. and Ratcliffe, J. (2009) The Role of Patient Preferences in Cost-Effectiveness Analysis: A Conflict of Values? PharmacoEconomics, 27, 705-712. https://doi.org/10.2165/11314840-000000000-00000

[15] Amoozegar, F. and Pringsheim, T. (2009) Rizatriptan for the Acute Treatment of Migraine: Consistency, Preference, Satisfaction, and Quality of Life. Patient Prefer Adherence, 3, 251-258.

[16] Ratcliffe, J., Chancellor, J., et al. (2004) Patients' Preferences for Characteristics Associated with Treatments for Osteoarthritis. Rheumatology, 43, 337-345. https://doi.org/10.1093/rheumatology/keh038

[17] McCaffrey, A.M., Pugh, G.F. and O’Connor, B.B. (2007) Understanding Patient 
Preference for Integrative Medical Care: Results from Patient Focus Groups. Journal of General Internal Medicine, 22, 1500-1505. https://doi.org/10.1007/s11606-007-0302-5

[18] Zenner, S.M. (1992) Application Possibilities of Traumeel S Injection Solution. Biological Therapy. Biological Therapy, X, No. 4.

[19] Birnesser, H., et al. (2004) The Homeopathic Preparation Traumeel ${ }^{\circledR}$ S Compared with NSAIDS for Symptomatic Treatment of Epicondylitis. Journal of Musculoskeletal Research, 8, 119.

[20] Sencer, S.F., Oberbaum, M., et al. (2012) Traumeel S in Preventing and Treating Mucositis in Young Patients Undergoing SCT: A Report of the Children's Oncology Group. Bone Marrow Transplantation, 47, 1409-1414. https://doi.org/10.1038/bmt.2012.30

[21] Lussignoli, S., Conforti, A., et al. (1999) Effect of Traumeel S ${ }^{\circledR}$, a Homeopathic Formulation, on Blood-Induced Inflammation in Rats. Complementary Therapies in Medicine, 7, 225-230. https://doi.org/10.1016/S0965-2299(99)80006-5

[22] Conforti, A., Benani, S., Metelmann, H., Chirumbolo, S., Lussignoli, S. and BclLalirc, P. (1997) Experimental Studies of the Anti-Inflammatory Activity of a Homeopathic Preparation. Biological Therapy, 15, 28-31.

[23] Heine, H. and Schmolz, M. (1998) Induction of the Immunological Bystander Reaction by Plant Extracts. Biomedical Therapy, XVI, 224-226.

[24] Heine, H. and Andră, F. (2002) The Antiinflammatory Action Mechanism of an Antihomotoxic Composite Remedy. Ärztezeitschrift für Naturheilverfahren, 43, 96-104.

[25] Li, Q. and Verma, I.M. (2002) NF-кB Regulation in the Immune System. Nature Reviews Immunology, 2, 725-734. https://doi.org/10.1038/nri910

[26] Bohmer, D. and Ambrus, P. (1992) Treatment of Sports Injuries with Traumeel Ointment. Biological Therapy, 10, 290.

[27] Schneider, C., Klein, P., et al. (2005) A Homeopathic Ointment Preparation Compared with 1\% Diclofenac Gel for Acute Symptomatic Treatment of Tendinopathy. Explore, 1, 446-452. https://doi.org/10.1016/j.explore.2005.08.010

[28] Thiel, W. (1994) The Treatment of Recent Traumatic Blood Effusions of the Knee, Joint. Biological Therapy, XII, 242-248.

[29] Porozov, S., Oberbaum, M., et al. (2004) Inhibition of IL- $1 \beta$ and TNF- $\alpha$ Secretion from Resting and Activated Human Immunocytes by the Homeopathic Medication Traumeel $^{\otimes}$ S. Clinical and Developmental Immunology, 11, 143-149. https://doi.org/10.1080/10446670410001722203

[30] Schneider, C., van Haselend, R., et al. (2008) The Role of a Homoeopathic Preparation Compared with Conventional Therapy in the Treatment of Injuries: An Observational Cohort Study. Complementary Therapies in Medicine, 16, 22-27. https://doi.org/10.1016/j.ctim.2007.04.004

[31] Singer, S.R., Amit-Kohn, M., et al. (2010) Traumeel $S^{\circledast}$ for Pain Relief Following Hallux Valgus Surgery: A Randomized Controlled Trial. BMC Clinical Pharmacology, 10, 9. https://doi.org/10.1186/1472-6904-10-9

[32] Žilinskas, J., Žekonis, J., et al. (2011) Total Antioxidant Capacity of Venous Blood, Blood Plasma, and Serum of Patients with Periodontitis, and the Effect of Traumeel S on These Characteristics. Medicina (Kaunas), 47, 193-199.

[33] Zenner, S.M. (1994) Therapy Experience with Homeopathic Ointment: Results of Drug Surveillance Conducted on 3422 Patients. Biological Therapy, XII, 204-211. 